\title{
A Review on Ethiopian Meat production trends, consumption and meat quality parameters
}

\author{
Addis Fikrie Birhanu \\ Cattle, camel and small animal meat product research and processing researcher, Ethiopian Meat and Dairy Industry \\ Development Institute, Bishoftu, Ethiopia. P.Box 1573
}

How to cite this paper: Birhanu, A.F. (2019) A Review on Ethiopian Meat production trends, consumption and meat quality parameters. International Journal of Food Science and Agriculture, 3(4), 267-274.

DOI: $10.26855 /$ ijfsa.2019.12.002

*Corresponding author: TAddis Fikrie Birhanu, Cattle, camel and small animal meat product research and processing researcher, Ethiopian Meat and Dairy Industry Development Institute, Bishoftu, Ethiopia P.Box 1573, Phone: - +251913794398.

Email: addsfkr@gmail.com

\begin{abstract}
Ethiopian meat production trends raising moderately with some fluctuation. The total meat production increase from 578,240 tons in 2004 to 749,430 tons in year 2010 and decreased to 597,765 tons in year 2017. Even though the country had huge number livestock population, the production of meat still low and contributed to about 0.2 percent of the world total meat production. This was due to low off-take rates, inability to fulfill international standard, legal and illegal live animal export. Ethiopia per capita of meat consumption is $8 \mathrm{~kg}$, which is the lowest as compared to developing countries $(77 \mathrm{~kg})$ and developed $(25 \mathrm{~kg})$. This is because of low per capita incomes, noncommercial oriented animal husbandry practices and high domestic meat prices. The most important meat quality parameters include $\mathrm{pH}$, colour, water holding capacity, tenderness, flavour, juiciness, cooking loss. These parameter affected by animal pre and post slaughter factor.
\end{abstract}

\section{Keywords}

Meat, Quality, production and consumption

\section{Introduction}

Ethiopia has one of the largest livestock populations in Africa and the tenth in the world. The country had 59.5 million heads of cattle, 30.70 million heads of sheep, 30.20 million heads of goats, 56.53 millions of poultry and 1.21 million heads of a camel [1] . Cattle in Ethiopia provide draught power, income for farming communities, means of savings and investment. It is central to the Ethiopian economy contributing about $45 \%$ to the agricultural GDP, supporting the livelihoods of $70 \%$ of the population, $18.7 \%$ to the national GDP and $16-19 \%$ to the total foreign exchange earning of the country [2].

Meat is the most valuable livestock product and for many people serves as their first-choice source of animal protein which provides all the essential amino acids and various micronutrients in proper proportion to the human beings. Meat defined as all animal tissues suitable as food for human consumption. This includes all processed or manufactured products prepared from animal tissues [3].

Meat production and consumption is an important in the Ethiopian economy. The annual contribution of ruminants to meat production in Ethiopia is estimated at over 3.2 million tones, representing over $72 \%$ of the total meat production. Cattle meat accounts for over $70 \%$ of the total red meat production and over $50 \%$ of the total meat output in SubSaharan Africa [4,5].

The Ethiopian meat export volume increased from 7,916 tons in 1999/2000 to 19,104.7 in 2018/2019. The Country's export performance reached its peak in $2016 / 17$ by exporting $19,779.20$ tons of meat. In the same period under review, the meat export (chilled shoats, beef carcass and offal) value has picked up from 1.7 million USD to 92.65 million USD [6]. Among these shoat carcass account 80.35 million dollar (86.72\%), beef carcass 6.23 (6.72\%) and offal 6.07 (6.55\%). There was no well organized information on Ethiopian meat production, consumption and meat quality. Therefore the 
objective of this manuscript was to review Ethiopia meat productions tends, consumption, meat quality parameters and suggest the possible intervention.

\section{Meat Production Trends in Ethiopia}

Meat production offers opportunity to serve a vast export market as well as Ethiopia's domestic market. The total meat production increase from 578,240 tons in 2004 to 749,430tons in year 2014 and decreased to 596,765 tons in year 2017 (Figure 1). Despite the fact that Ethiopia is the tenth largest livestock population in the world, the production of meat is still low and contributed to about 0.2 percent of the world total meat production, of which most is sheep and goat meat. This ranked Ethiopia the $55^{\text {th }}$ largest meat producing country in the world. The reasons behind low production of meat in Ethiopia are due to low off-take rates, most animals slaughtered and exported live were not produced in commercially oriented manner and sell only in need of cash or when animals get too old after serving for draft purpose and inability to fulfill minimum standard required in the international market for processed meat. The trend of meat production in Ethiopia shows it was rising moderately, of course with some fluctuations from 2004 to 2017 [7].

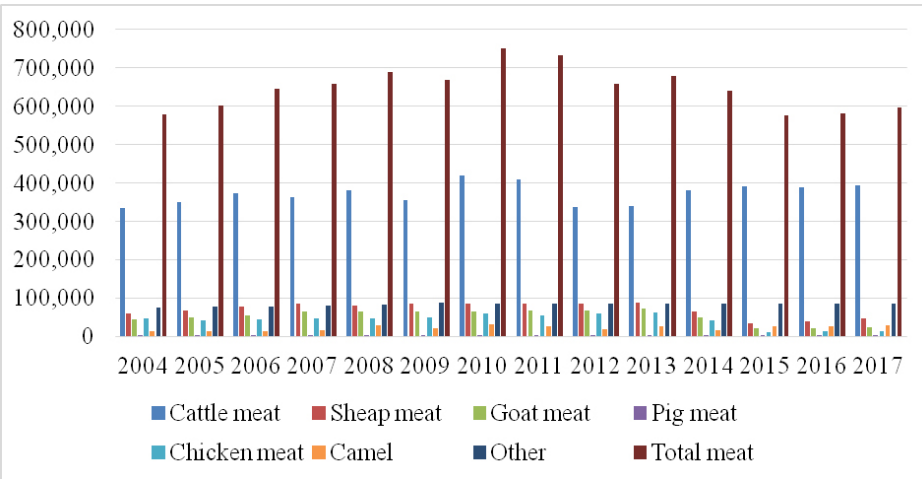

Figure 1. Meat production trends by type in Ethiopia (in tons).

\section{Domestic Meat Consumption in Ethiopia}

The domestic meat demand is believed to increase with increasing population, urbanization, and income in general and particularly for beef due to preference for eating meat. Meat consumption is often an indicator of economic status of a country or an individual. People with a higher social or economic status demand a greater amount of high-quality meat products (Ameha, 2008). The per capita consumption of meat in developed countries is much higher than in developing countries. Countries whose population consumes the least amount of meat are located in Africa and Asia. Developed countries consumed a consistent level of $77 \mathrm{~kg}$ of meat per capita annually, while developing countries struggled to maintain a diet with only $25 \mathrm{~kg}$ of meat per capita annually. With the fast growth of Ethiopian economy and population, the domestic demand for meat is increasing; however, the country is one of the lowest per capita of meat consumption in the world which is $8 \mathrm{~kg}$, of which about $5.3 \mathrm{~kg}$ comes from beef. This is due to low per capita incomes, non-commercial oriented animal husbandry practices, high domestic meat prices and the fasting days over 200 days per year by the Orthodox Christians [8].

\section{Meat Quality}

Meat quality is a broad term and covers a variety of characteristics. [9] defined meat quality on the basis of its conformational and functional qualities. Functional qualities as the desirable attributes of a product while the conformance qualities take into consideration producing products that exactly meets consumer's specifications. Meat quality is a function of tenderness, $\mathrm{pH}$, colour, juiciness, flavour and nutritive value [10]. Quality attributes primary affected by transport and handling in cattle include $\mathrm{pH}$, colour, tender, texture and moisture and degradation of these variables is collectively referred to as dark firm and dry, high $\mathrm{pH}$, and low glycogen meat [11].

Appearance quality such as colour is measured instrumentally. However, other aspects (juiciness and flavour) require a subjective approach, and the best ways to evaluate meat quality are scores of trained taste panelists who evaluate different components of meat eating quality. Meat with good sensory properties is what consumers' desire, so beef industry must supply meat with these attributes on a consistent and uniform basis [12]. 
Carcass fat proportion, especially intramuscular fat (marbling), plays an important role in the meat sensory characteristics [12], since it contributes directly to its sensory properties. Based on this observation, marbling score has been used by the US beef industry as the primary predictor of beef meat quality [13].

Hygienic quality covers wholesomeness and safety aspects, particularly contamination with pathogens and potential presence of unwanted chemical residues such as antibiotics, sulfonamides and other pesticides, heavy metals and mycotoxin [14].

\subsection{Meat pH}

The most important meat quality indicator is the $\mathrm{pH}$ value, which is related to biochemical processes during the transformation of muscle to meat. Consequently, changes in the $\mathrm{pH}$ during the postmortem period influence the organoleptic characteristics of the meat. The $\mathrm{pH}$ value of meat closely correlated with many other properties of meat such as water-holding capacity, color, tenderness, flavor and shelf-life [15].

The meat $\mathrm{pH}$ provides valuable information about postmortem muscle glycolysis, thus enabling to detect quality defects of meat such DFD [16]. The $\mathrm{pH}$ of the meat vary due to factor such as pre-slaughter stress, chilling temperature, season and animal factor such as age, breed and sex. The ultimate $\mathrm{PH}$ is determined 24 hours post-slaughter using a $\mathrm{pH}$ meter. The muscle of a living animal has a $\mathrm{pH}$ of 7.1. The $\mathrm{pH}$ range of normal meat of an unstressed animal is 5.4-5.7. After slaughtering, some of the glycogen in the meat turns into lactic acid. As a result, the $\mathrm{pH}$ value is lowered. The extent to which $\mathrm{pH}$ is lowered after slaughter depends on the level of stress induced during transportation and pre-slaughter procedure ,the amount of glycogen in the muscle prior to the animal's death ,and the rate of glycolysis $[3,9]$. The rate of post-mortem glycolysis may be too fast, leading to a rapid drop in $\mathrm{pH}$, or too slow, resulting in too high ultimate $\mathrm{pH}$ [15].

\subsection{Colour of Meat}

Meat color is an important parameter in meat quality. It is an important characteristic of meat that influences consumers purchasing decisions because consumers use meat color as an indication of freshness and quality [17]. Fresh meat has a bright red color due to the presence of oxymyoglobin which results from the combination of myoglobin with oxygen. It is normal for meat to change color depending on the presence or absence of air. Colour of meat depends upon several individual factors and their interactions, and concentration of meat pigments, essentially myoglobin and the chemical state of myoglobin [18].

Differences in meat colour have been associated with variations in intramuscular fat and moisture content, age dependent, muscle-fibre type and changes in muscle myoglobin content. Color is also greatly affected by muscle $\mathrm{pH}$. At a high pH, muscle has a closed structure, and hence, appears dark and the meat tends to be tough [19]. Myoglobin is the basic pigment in fresh meat and its content varies with production factors such as species, animal age, sex, feeding systems, type of muscle and muscular activity [20] .The color of fresh meat is species-dependent In pork, lighter flesh, which is greyish-pink in color, is considered acceptable to consumers, whereas fresh meat from ruminant livestock (beef, lamb, and chevon) is darker than pig meat, and a bright cherry-red color is deemed acceptable in these species. Meat color differences between species are largely due to the differences in Myoglobin content [21,22].

The concentration of Myoglobin in meat increases as animal age increases [23]. Older animals had darker (lower $L^{*}$ values) and redder (higher $a^{*}$ values) meat than younger animals [22] .Fat deposits also tend to become more yellow in color over age due to an increase in carotenoid deposits [24], which may also affect the perceived color of meat. Regarding to sex the meat from intact male animals is darker [25] than meat from females and castrated males, which is attributed to higher concentrations of myoglobin in intact males likely due to greater levels of physical activity.

Considering feeding system pasture-finished animals had high myglobin content than grain (concentrate) based system due to high muscular iron (pigment) concentrations in pasture as compared to grain feed [17]. Difference in colour between different types of muscle due to difference in muscle fiber which influences the amount of myglobin present. Muscles with higher proportion of oxidative fibers are a darker, deep red color in comparison to those with higher proportion of glycolytic fibers due to high myoglobin content [26]. Pre-slaughter handling factors such as loading, transportation, unloading, distance traveled and time spent in the lairages, the procedure and method of slaughtering also affect the colour [27).

The colour of meat can be measured numerically using a colorimeter or subjectively. It usually measured by the $L^{*}$, $a^{*}, b^{*}$ colour space system, which was developed by the International Illumination Commission (CIE; Commission Internationale del'Eclairage) in the year 1976 [28]. $L^{*}$ value indicates the lightness of the meat and it ranges from 0 (all 
light absorbed-black) to 100 (all light reflected-white). The $a^{*}$ is the redness of meat and it ranges from -60 (green) to + 60 (red) and the $b^{*}$ represent yellowness and it ranges from -60 (blue) to +60 (yellow):[29].

\subsection{Water Holding Capacity of Meat}

WHC of meat is one of the most important factors of meat quality because it influences consumer acceptance and the final weight of the product. It refers to the ability of meat to retain its own water content when subjected to external force during cutting, heating, grinding and pressing [30, 31]. Many physical properties of meat such as colour, texture and firmness of raw meat, juiciness and tenderness of cooked meat are partially dependent on water holding capacity [32]. Meats of adult mammalian muscle contain $70-75 \%$ water. Muscle proteins are capable of holding water molecules to their surface. This water exists in three forms; bound water, immobilized water and free water. Bound water is tightly bound to proteins and is not free to move around and cannot be frozen. It is estimated as the amount of water remaining in meat after it has been subjected to some kind of physical pressure. Bound water has been determined to account for the smallest portion of water found in muscle (1-2\% or $0.5 \mathrm{~g}$ of water for every gram of protein). Immobilized water has a weaker attraction to proteins than bound water and can move away from proteins but not easily. It represents approximately $85 \%$ of water in muscle. Free water is the fraction of water that can flow unimpeded from the tissue .The majority of all water held is loosely by proteins and moves easily due to weak attraction force and is therefore an important determinant of WHC [33].

The WHC is determined at $24 \mathrm{~h}$ post mortem. The two methods that are in common use for the estimation of water holding capacities are Press method and Centrifugal method. The press or the filter-paper wetness (FPW) method, described by [34] is recognized as the simplest, less cost and fastest technique to evaluate the meat WHC. This method has been used to evaluate the amount of "squeezable" water. The sample is compressed between two glass plates and subjected to a specified pressure for a given time. After compression the free water squeezed out on a pre weighted filter paper [35]. A number of pre-and post-mortem factors influence WHC of meat. Among pre-slaughter factor age, genotype and stresses on the animal such as fasting, lack of sufficient rest or extreme hot or extreme humid air condition and different stunning methods have been play a large role in influencing WHC of the meat [36] .Chilling, ageing, injecting non-meat ingredients and cooking procedure have been influences water holding capacity in the post-slaughter period. All of these factors have the potential to greatly influence the rate and extent of $\mathrm{pH}$ decline, and thus the water-holding capacity of the meat [28].

\subsection{Tenderness}

Tenderness is defined as the ease of mastication, which involves the initial ease of penetration by the teeth, the ease with which the meat breaks into fragments and the amount of residue remaining after mastication [37].Tenderness is one of the most important meat palatability attributes, and consumers are willing to pay more for beef which is tender [38]. Meat tenderness is the most difficultly predicted trait, but it is very important to meat quality and consumer acceptance. Tenderness is based on ease of chewing that is contributed by many factors. Among them, the fibrous nature of muscle contributes to chewing resistance [39].The fact that many myofibrils are arranged across the muscle fibers leads to more strength for muscle and decreases muscle tenderness. Variation in beef tenderness may be attributed to breed (genetic status), age, carcass composition (marbling), and environmental factors (time on feed, implants and pre-slaughter stress).

A study conducted by [40] have shown that meat obtained from Bos indicus tougher than Bos taurus, due to lower proteolysis of myofibrillar proteins, as a result of the higher activity of calcium-dependent protease inhibitor (calpastatin). Regarding to age the older the animal, the tougher the meat in general because amount of connective tissues (insolubility of collagen) increase with age. The greatest tenderness and quality of beef is achieved with cattle less than 36 months of age there after the meat become tougher [41].

longer time on feed had positive effects of on tenderness, marbling and sensory characteristics of beef [42]. However, animals that are finished on concentrate feed tend to reach a given slaughter weight sooner than animals that are finished on the pasture. Thus, concentrate-fed animals usually are slightly tender because they are slaughtered at younger age. Another factor such as stressing an animal before slaughter causes a number of biochemical effects on muscle, shortening the muscle fibers (sarcomeres) leading to meat toughness. Stressed animals before slaughter present increased Warner-Bratzler shear force values, and produce tougher beef [43].

tenderness, measured by shear force, increases when better marbling is attained [44]. The connective tissue rigidity is 
weakened with increase marbling accumulation resulting in tender meat .Variation in meat tenderness is the main factor for consumer dissatisfaction; hence this trait must be controlled in order to improve customer satisfaction and decision to repurchase [38].

\subsection{Flavour}

Flavour is the very important components of the eating quality of meat. The flavour of meat, is a combination of its taste and aroma or smell, and influenced by sensations such as mouth feel and juiciness [45]. It is a subjective property and difficult to evaluate. flavour is thermally derived, since uncooked meat has little or no aroma and only a blood-like taste. There are a lot of compounds present in meat which contribute to the flavour, and many of these compounds are altered during storage and cooking. Among these, the proportion of different fatty acids in the fat, and, in particular, the unsaturated fatty acids, which are more susceptible to oxidation to volatile compounds, such as aldehydes, ketones hydrocarbons and alcohols, are the most common. Phospholipids, which are rich in polyunsaturated fatty acids, also play a fundamental role in the flavour of meat [46].

During cooking, a complex series of thermally induced reactions (Maillard reaction) occur between non-volatile components of lean and fatty tissues resulting in a large number of reaction products. Although the flavour of cooked meat is influenced by compounds contributing to the sense of taste, it is the volatile compounds, formed during cooking, that determine the aroma attributes and contribute most to the characteristic flavours of meat [47]. Breed, sex, nutrition, and post slaughter treatments of the carcass, can all affect carcass fat and hence the flavour of the meat. The flavour intensity increases with increasing age of an animal regardless of the type of animal. Generally, meat from an older animal of the same species exhibits stronger flavour than meat from a young animal [48].

\subsection{Juiciness}

Juiciness is an important factor in the eating quality of meat and playing a major a role in meat texture. It is a subjective sensory trait which determined by consumers or sensory panels. [49]. Meat juiciness is defined as the impression of moisture and lubrication when meat is chewed in the mouth. Meat juiciness can be separated into two components. The first being the impression of wetness during the initial chews, produced by the rapid release of meat fluids, and it related to the water content of the meat. The second component is the impression of juiciness during sustained chewing and is thought to be related to the fat content of the meat [50]. Hence, water retained in the meat and lipids or fat determine the juiciness of meat.

There are numerous factors which affect meat juiciness. These factors include ultimate $\mathrm{pH}$, fat content, enhancement level, cooking method, and end point temperature or degree of doneness [51].The higher end-point temperature, the more the cooking loss and the lower the juiciness [52]. With Increased amounts of intramuscular fat the meat juiciness also increased [53] increase juiciness of meat, the most important factor must be to educate consumers not to over-cook the meat

\subsection{Cooking loss (CL)}

Cooking is a process of heating beef at sufficiently high temperatures that denatures proteins and makes it less tough and easy to consume [54]. It can be achieved either by boiling or by roasting [55] and in all cases losses occur. Cooking loss is one of the meat quality parameters that not given too much consideration by meat processors and consumers due to inappropriate cooking time and temperature. It refers to the reduction in weight of meat due to evaporative (volatile) and drip loss during the cooking process [56]

Drip losses is the combination of juices and fat that drip from meat during cooking while Evaporative losses is the losses of weight from meat during cooking as a result of evaporation.

During cooking process all water-soluble vitamins, minerals, some parts of soluble proteins has been susceptible to losses. The increased loss of such nutrients deteriorates the meat nutritional quality and has large substantial economic loss to beef industry [19]. Cooking loss affected by many factors such as cooking temperature, time, meat $\mathrm{pH}$, collagen content, ageing and the state of the meat before it is cooked -frozen versus thawed [49] .Meat cooked at high temperature had lower meat yield with more cooking loss, less moisture and less protein content [57,58]. This high temperature causes denaturation of myofi-brillar proteins, primarily the actomyosin complex, and consequently results in shrinkage of the muscle fiber which causes loss of meat liquid which results in mass loss [59]. Other factors such as breed age and cooking method also affect cooking loss [60, 61]. 


\section{Conclusion and Recommendation}

This study tried to review the meat production and consumption in Ethiopia and focus on meat quality parameters. The current meat production through the country is low as compared to existing livestock population and other African counties which had low number of livestock. The meat consumption is also very low. Meat quality parameters ( $\mathrm{pH}$, colour, water holding capacity, tenderness, flavour, juiciness, and cooking loss affected by animal factor (Age, breed, sex), pre-slaughter (feeding, handling and transportation) and post slaughter factors (chilling, aging \& cooking). There is need to conduct further research on the effect of these factor and their interaction on meat quality. For Ethiopian in order to improve meat production and quality there is need to improve animal breeding thorough implementing breeding strategy, improve Animal heath, livestock transportation system , feed quality and supply

\section{Conflict of Interest}

There was no conflict of interest regarding to this review

\section{Reference}

[1] CSA (Central Statistical Agency). 2017. Agricultural Sample Survey 2016/2017. Report on Livestock and Livestock characteristics. Statistical bulletin, Vol II: 585, Addis Ababa, Ethiopia.

[2] MoA (Ministry of Agriculture (2012) Livestock growth strategy and action. Ethiopia, Addis Ababa

[3] Ameha Sebsibe (2008) Sheep and Goat Meat Characteristics and Quality. Sheep and Goat Production Handbook for Ethiopia. Ethiopian Sheep and Goats Productivity revieImprovement Program (ESGPIP), Addis Ababa, Ethiopia. PP.323-328.

[4] EARO (1999) Livestock research strategy (unpublished), Addis Ababa, Ethiopia.

[5] FAOSTAT (Food and Agriculture Organization of the United Nations Statics). 2013. http://faostat.fao.org.

[6] EMDTI (Ethiopian meat and dairy industry development institute) (2019) Unpublished annual report.

[7] FAOSTAT (Food and Agriculture Organization of the United Nations Statics) (2016)

[8] http://faostat.fao.org.

[9] Warriss, P. D( 2000) Meat science: An introductory text. CAB International Publishing, Wallingford, England.

[10] Webb, E.C. and Onell, H. A (2008)The animal fat paradox and meat quality. PP 28-36. In: USDA (eds.), United States standard for grades of carcass beef, USA.

[11] Ponnampalam, E.N., Hopkins, D.L., Bruce,H., Li,D., Gianluca, B. and Bekhit, E.D (2017) Causes and contributing factors to dark cutting meat: Current Trends and Future Directions. Comprehensive review in food science and safety, 16:400-410.

[12] Fergusson, D.M. (2004) Objective on-line assessment of marbling: a brief review. Australian Journal of Experimental Agriculture, 44: 681-685.

[13] USDA (United State Department of Agriculture) (1997) United States Standards for Grades of Carcass Beef. United States Department of Agriculture, Agricultural Marketing Service, Washington DC, USA.

[14] Aberle, E.D., Reeves, E. S., Judge, M. D., Hunsley., R. E. and Perry, T.W (2001) Palatability and muscle characteristics of cattle with controlled weight gain: time on high energy diet. Journal of Animal Science, 52(4): 757-763.

[15] Knox, B.L., Vanlaack R.L. and Davidson, P.M (2008) Relationship between ultimate pH and microbial, chemical and physical characteristics of vacuum-packaged pork loins. Journal of Food Science, 73(3): 104-110.

[16] Rammouz, E.R., Berri, C., Bihanduval, E.L., Babile, R. and Fernandez X. (2004). Breed differences in the biochemical determinism of ultimate $\mathrm{pH}$ in breast muscles of broiler chickens. A key role of AMP deaminase. Poultry Science 83(8):1445-1451.

[17] Ponnampalam, E.N., Butler, K.L., Burnett, V.F., Mcdonagh, M.B., Jacobs, J.L. and Hopkins, D.L (2013) Aged vacuum packaged lamb cuts are less brown than fresh muscle cuts under simulated retail display. Food Nutrition Science, 4:147-153. 
[18] Ronsevold, K. and Anderson, H. J (2003) Factors of significant for pork quality review. Meat Science, 64(3), 219-337.

[19] Muchenje V., Jama, N., Chimonyo M., Strydom., P. E, Dzama K and Raats, J. G. (2008) Cooking loss components of beef from Nguni, Bonsmara and Angus steers African Journal of Agricultural Research. Vol. 3 (6), pp. 416-420.

[20] Muchenje, V., Chulayo, A.Y. and Mpakama, T. 2014. Bruising in slaughter cattle and its relationship with creatine kinase levels and beef quality as affected by animal related factors. Asian-Australian Journal of Animal Science, 27(5):717-25.

[21] Aalhus J. L., cocolin L, Legarreta I.G, Nollet L.M, Purchas RW, Schilling M.W, Stanfield F, Xiold Y.L. Meat and Meat processing (2012). edited by Hui Y.H.

[22] Warriss, P. D., S. N. Brown, S. J. M. Adams, and D. B. Lowe (1990) Variation in haem pigment concentration and colour in meat from British pigs. Meat science, 28:321-329.

[23] Cho, S., G. Kang, P. N. Seong, B. Park, and S. M. Kang (2015) Effect of slaughter age on the antioxidant enzyme activity, color, and oxidative stability of Korean Hanwoo (Bos taurus coreanae) cow beef. Meat Science, 108:44-49.

[24] Lawrie, R. A., and D. A Ledward (2006) Lawrie's meat science. 7th ed. Woodhead Publishing Ltd., Cambridge, UK.

[25] Sigge, G.O., Neethling, N.E., Suman ,S.P., Hoffman L.C and Hante, M.C (2017) Exogenous and Endogenous Factors Influencing Color of Fresh Meat from Ungulates. Meat and Muscle Biology.

[26] Kirchofer, K. S., C. B. Calkins, and B. L. Gwartney (2002) Fiber- type composition of muscles of the beef chuck and round. Journal of Animal Science, 80:2872-2878.

[27] Roth, B., Imsland, A., Gunnarsson, S., Foss, A. and SchelvisSmith, R (2007) Slaughter quality and rigor contraction in farmed turbot (Scophthalmus maximum) between different stunning methods. Bulletin of Aquaculture, 272(1):754-761

[28] Joseph, P. Kerry and David, Ledward (2009) improving the sensory and nutritional quality of fresh meat, 1 st edition, Wood head Publishing Limited and CRC Press LLC, Cambridge, England.

[29] Simela, L (2005) Meat characteristics and acceptability of chevon from South African Indigenous goat. M.Sc. Thesis, University of Pretoria, South Africa.

[30] Pearce, K.L., Rosenvold, K., Andersen, H.J., Hopkins, D.L (2011) Water distribution and mobility in meat during the conversion of muscle to meat and ageing and the impacts on fresh meatquality attributes e a review. Meat Science 89, 111-124.

[31] Khastrad ,sarbalnl, Arfa'l and Rustdlmansyah (2017). Effect of cattle breeds on meat quality of longissimus dorsi muscle. Pakstan journal of nutrition, 16: 164-167.

[32] Joseph, P. Kerry and David, Ledward (2009) improving the sensory and nutritional quality of fresh meat, 1 st edition, Wood head Publishing Limited and CRC Press LLC, Cambridge, England.

[33] Huff Lonergan, E., and Lonergan, S. M (2005) Mechanisms of water-holding capacity of meat: The role of postmortem biochemical and structural changes. Meat Science, 71(1): 194-204.

[34] Kauffman. R. G, Eikelenboom, G., Vanderwal, P.G., Merkus, G. and Zaar, M (1986) the use of filter paper to estimate drip loss of porcine musculature, Meat Science, 18(3):191-200.

[35] Trout, G.R (1988)Techniques for measuring water binding capacity in muscle foods- a review of methodology. Meat Science, 23:235-252.

[36] Lomiwes, D (2008) Rapid on-line glycogen measurement and prediction of ultimate $\mathrm{pH}$ in slaughter beef. Doctoral dissertation, Auckland University of Technology, Auckland, New Zealand.

[37] Lawrie, R. A (1998) Lawrie's Meat Science, 6th ed. Technomic Publishing Company Inc, Lancaster, PA.

[38] Farzad, S (2014) Prediction of Beef Tenderness using Hyperspectral Imaging. Thesis submitted to the Graduate and Postdoctoral Studies Office in partial fulfillment of the requirements for the degree of Master of Science. Mc Gill University, Sainte-Anne de ellevue, Canada.

[39] Gerrard, D. E., A. L. Grant (2003) Principles of animal growth and development, Kendall/Hunt Publishing

[40] Wheeler,T.L., Cundiff, L.V.,Shackelford,S.D.,Koohmaraie,M.2005. Characterization of biological types of cattle 
(Cycle VI): Carcass, yield, and longissimus palatability traits. Journal of Animal Science, 82: 1177-1189.

[41] Berit, C (2012) The effect of biochemical parameters on tenderness in beef. Master Thesis 30 Credits.

[42] Sami, A.S., Augustini, C. and Schwarz, F.J (2004) Effects of feeding intensity and time on feed on performance, carcass characteristics and meat quality of simmental bulls. Meat Science, 67(2):195-201.

[43] Hwang, I.H., Park, B.Y., Chalo, S.H., and Lee, J.M (2004). Effects on muscle shortenning and proteolyisis on Warner-Bratzler shear force in beef longissimus and semitendinosus. Meat Science, 68(3): 497-505.

[44] killiner, K.M., Calkins, C.R., Umberger, W.J., Feuz.D.M., Eskridge, K.M. 2004. Consumer sensory acceptance and value for beef steaks of similar tenderness, but differing in marbling level. Journal of Animal Science, 82(11): 3294-3301

[45] Robbins, K., J. Jensen, K.J. Ryan, C. Homco-Ryan, F.K. McKeith, and M.S. Brewer (2003) Consumer attitudes toward beef and acceptability of enhanced beef. Meat Science, 65:721-729.

[46] Calkins, C. R. \& Hodgen, J. M (2007) A fresh look at meat flavor. Meat Science, 77:63-80. Farmer, L.J. 1992. Meat flavour. PP. 169-182. In: Johnston, D.E., Knight, M.K. and Ledward, D.A. (eds.), The Chemistry of Meat-based Foods. Royal Society of Chemistry, Cambridge.

[47] Mottram, D.S (1998) Flavour formation in meat and meat a review. Food Chemistry, 62(4): 415- 424

[48] Young, O.A., Berdague, J. L., Viallon, C., Rousset-Akrim, S. and Theriez, M (1997) Fat-borne volatiles and sheep meat odour. Meat Science, 45: 183-20.

[49] Robyn, D.W (2017) The Eating Quality of Mea- IV Water-Holding Capacity and Juiciness. Research gate. DOI: 10.1016/B978-0-08-100694-8.00014-5.

[50] Winger, R.J., Hagyard, C.J (1994) Juicinesse its importance and some contributing factors. In: Pearson, A.M., Dutson, T.R. (Eds.), Advances in Meat Research, Quality Attributes and Their Measurement in Meat, Poultry and Fish Products, vol. 9. Chapman and Hall, New York.

[51] Montgomery, T. H., and J. M. Leheska (2008) Effects of various management practices on beef-eating quality

[52] Aaslyng, M.D., Bejerholm, C., Ertbjerg, P., Bertram, H.C., Andersen, H.J (2003) Cooking loss and juiciness of pork in relation to raw meat quality and cooking procedure. Food Quality and preference 14, 277-288

[53] Aaslyng, M.D and Bejerholm, C (2004) The influence of cooking technique and core temperature onresults of a sensory analysis of pork depending on the raw meat quality. Food Quality and Preference 15, 19-30.

[54] Garcia-Segovia P, Andres-Bello A, Martinez-Monzo J (2006) Effect of cooking method on mechanical properties, colour, and structure of beef muscle (M. pectoralis). Journal of Food Engineering 80 (3): 813-821.

[55] Shilton N, Mallikarjunan P, Sheridan P (2002) Modeling of heat transfer and evaporative mass losses during the cooking of beef patties using far-infrared radiation. Journal of Food Engineering, 55: 217-222.

[56] Vasanthi C, Venkataramanujam V, Dushyanthan K (2006) Effect of cooking temperature and time on the physicochemical, histological and sensory properties of female carabeef (buffalo) meat. Meat Scince, 76 (2): $274-280$.

[57] Ramani.R (2013) Carcass characteristics and meat quality of emus -a pilot study. PhD thesis, Tamil Nadu Veterinary and Animal Sciences University.

[58] Nithyalakshmi, V. and Preetha, R. (2015) Effect of cooking conditions on physico-chemical and textural properties of emu (dromaius novaehollandiae) meat. international food research journal 22(5): 1924-1930.

[59] Wyrwisz, J., Poltorak, A., Polawsk, E., Pierzchala, M., Jozwik, A., Zalewska, M., Zaremba, R. and Wierzbicka, A(2012) The impact of heat treatment methods on the physical properties and cooking yield of selected muscles from Limousine breed cattle. Animal Science Papers and Reports. Institute of Genetics and Animal Breeding, Jastrzębiec, Poland 30 (4): 339 -351.

[60] Khastrad ,sarbalnl, Arfa'l and Rustdlmansyah (2017) Effect of cattle breeds on meat quality of longissimus dorsi muscle. Pakstan journal of nutrition, 16: 164-167.

[61] Birmaduma, G., Yesihak. Y, Mohammad. Y (2019) Evaluation of Eating Quality in Sensory Panelist and Instrumental Tenderness of Beef from Harar, Arsi and Bale Cattle Breeds in Oromia, Ethiopia. International Journal of agricultural science and Food Technology. DOI: https://dx.doi.org/10.17352/ijasft. 